\title{
O direito à Educação Infantil: avanços legais e desafios para a efetivação do direito das crianças do Município João Pessoa - Paraíba
}

The right to Childhood Education: legal advances and challenges for the realization of children's rights in João Pessoa - Paraíba

El derecho a la Educación Infantil: avances legales y desafíos para la realización de los derechos del niño en João Pessoa - Paraíba

\author{
Jéssica Nascimento Martins \\ ORCID: https://orcid.org/0000-0002-0703-9050 \\ Universidade Federal da Paraíba, Brasil \\ E-mail: jessicajnm@hotmail.com \\ Déborah Kallyne Santos da Silva \\ ORCID: https://orcid.org/0000-0002-7930-0852 \\ Universidade Federal da Paraíba, Brasil \\ E-mail: kall.ld@hotmail.com \\ Alice Maria André Dias \\ ORCID: https://orcid.org/0000-0001-5693-6834 \\ Universidade Federal da Paraíba, Brasil \\ E-mail: alicedias60@hotmail.com \\ Francyllayans Karla da Silva Fernandes \\ ORCID: https://orcid.org/0000-0002-9690-464X \\ Universidade Federal da Paraíba, Brasil \\ E-mail: francyllayans@gmail.com \\ Priscila Morgana Galdino dos Santos \\ ORCID: https://orcid.org/0000-0002-6295-8076 \\ Universidade Federal da Paraíba, Brasil \\ E-mail: priscila2085@hotmail.com \\ Janine Marta Coelho Rodrigues \\ ORCID: https://orcid.org/0000-0002-9457-9070 \\ Universidade Federal da Paraíba, Brasil \\ E-mail: jmcoelho@ig.com.br
}

\begin{abstract}
Resumo
O presente trabalho tem como objetivo analisar os avanços legais e os desafios frente à efetividade do direito da criança à Educação Infantil no município de João Pessoa/PB. Os avanços presentes na legislação educacional que caminharam para assegurar a educação como direito subjetivo de todos e elemento essencial para a construção material e cultural não anulam a necessidade de uma melhor compreensão de como este direito tem sido concretizado para as crianças, especificamente na Educação Infantil. Assim sendo, a questão problema analisa como vem acontecendo a efetivação do direito das crianças à Educação Infantil no Município de João Pessoa (PB). Para tal, trazse como aporte teórico acerca do direito da criança à educação Dias (2008), Ruiz (2007) e Fernandes \& Candau (2017). A fim de atingir o objetivo proposto e tendo como caminho metodológico a pesquisa qualitativa, documental e bibliográfica, o estudo se deteve aos documentos oficiais, à legislação nacional vigente acerca da Educação Infantil e à observação de dados oficiais que retratam o cenário educacional. Como resultados, no âmbito do município de João Pessoa/Paraíba, infere-se que, apesar dos significativos avanços, o atual panorama revela a defasagem na oferta da Educação Infantil, bem como a não efetivação, em sua plenitude, do direito à educação da criança pequena.
\end{abstract}

Palavras-chave: Educação infantil; Direito à educação; Avanços; Desafios.

\begin{abstract}
This paper aims to analyze the legal advances and challenges regarding the effectiveness of the child's right to early childhood education in the city of João Pessoa / PB. The advances in educational legislation that have moved towards ensuring education as a subjective right for everyone and an essential element for material and cultural construction do not negate the need for a better understanding of how this right has been realized for children, specifically in early childhood education. Therefore, the problem question analyzes how the right of children to Early Childhood Education in the Municipality of João Pessoa (PB) has been taking place. To this end, it is brought as theoretical support about the child's right to education Dias (2008), Ruiz (2007) and Fernandes \& Candau (2017). In order to achieve the proposed objective and using qualitative, documentary and bibliographic research as a methodological
\end{abstract}


path, the study focused on official documents, current national legislation on early childhood education and observation of official data that portray the educational scenario. As a result, within the scope of the municipality of João Pessoa / Paraíba, it appears that, despite the significant advances, the current panorama reveals the gap in the provision of early childhood education, as well as the failure to fully realize the right to education for little child.

Keywords: Infant education; Right to education; Advances; Challenges.

\section{Resumen}

Este trabajo tiene como objetivo analizar los avances y desafíos legales sobre la efectividad del derecho del niño a la educación infantil en la ciudad de João Pessoa / PB. Los avances en la legislación educativa que han avanzado hacia la garantía de la educación como un derecho subjetivo de todos y un elemento esencial para la construcción material y cultural, no niegan la necesidad de comprender mejor cómo se ha realizado este derecho para los niños, específicamente en la educación infantil. Por tanto, la pregunta problema analiza cómo se ha venido gestando el derecho de los niños a la Educación Infantil en el Municipio de João Pessoa (PB). Para ello, se presenta como soporte teórico sobre el derecho del niño a la educación Dias (2008), Ruiz (2007) y Fernandes \& Candau (2017). Para lograr el objetivo propuesto y utilizando la investigación cualitativa, documental y bibliográfica como camino metodológico, el estudio se centró en los documentos oficiales, la legislación nacional vigente en educación infantil y la observación de datos oficiales que retratan el escenario educativo. Como resultado, en el ámbito del municipio de João Pessoa / Paraíba, parece que, a pesar de los importantes avances, el panorama actual revela la brecha en la provisión de educación infantil, así como la falta de realización plena del derecho a la educación de los niños.

Palabras clave: Educación infantil; Derecho a la educación; Avances; Retos.

\section{Introdução}

Nos últimos tempos, a educação para as crianças foi ganhando significativos espaços no marco da legislação educacional. Os avanços educacionais que procuram garantir o direito à educação das crianças pequenas são resultados dos construtos históricos e da luta dos trabalhadores da educação mobilizados nas suas organizações acadêmicas e classistas. Nesse rol de avanços educacionais podemos citar o lugar que a Educação Infantil conquistou no campo das políticas públicas; o reconhecimento da criança como sujeito de direitos; o reconhecimento da Educação Infantil como primeira etapa da Educação Básica e a sua inserção no fundo nacional de financiamento educacional, entre tantas outras conquistas alcançadas.

Esses avanços têm, como marco teórico, as discussões acontecidas na Assembleia Nacional Constituinte de 19871988 cuja finalidade foi elaborar, debater e aprovar um novo marco legal, de natureza constitucional, após o Brasil deixar para trás mais de vinte anos de ditadura militar. Assim sendo, a Constituição Federal de 1988 é considerada pelos especialistas educacionais como o novo marco jurídico e legal que passa a regulamentar, dentre outras finalidades, a educação como um todo e, em particular, a Educação Infantil.

Nesse ínterim, a educação, sendo o marco deste texto, é considerada um elemento necessário para a construção do mundo material e cultural da humanidade, além de ser essencial para a formação humana, já que seu objetivo diz respeito à identificação "[...] dos elementos culturais que precisam ser assimilados pelos indivíduos da espécie humana para que se tornem humanos" (Saviani, 2013, p. 13).

Para o Direito Internacional (protetor dos direitos dos homens), o reconhecimento do direito à educação pela Declaração Universal dos Direitos Humanos se constituiu um grande feito. O direito à educação, em âmbito internacional, instituiu-se como um enorme desafio e passou a ser anunciado nos principais dispositivos jurídicos, dentre eles a Declaração Universal dos Direitos Humanos de 1948, a Declaração Americana sobre Direitos e Deveres do Homem (1948), o Pacto Internacional dos Direitos Econômicos, Sociais e Culturais (1966); a Declaração sobre o Progresso e Desenvolvimento no Social (1969), a Convenção das Nações Unidas sobre os Direitos das Crianças (1989), a Declaração Mundial sobre a Educação para Todo: satisfação das necessidades básicas de aprendizagem (1990), a Declaração e Programa de Ação da Conferência Mundial sobre os Direitos Humanos (1993) e o Plano de Ação para a Década das Nações Unidas para a Educação no Domínio dos Direitos Humanos (1995-2004).

No caso do Brasil, essa perspectiva começa a tomar corpo logo após a aprovação da Constituição Federal de 1988 
(CF/88), a qual passou a ser conhecida como Constituição Cidadã, um novo marco legal e pedagógico que começa a regulamentar a educação nacional e, em particular, a Educação Infantil até os dias de hoje.

As considerações supracitadas conduziram a elaboração da seguinte questão norteadora: como vem acontecendo a efetivação do direito das crianças à Educação Infantil no Município de João Pessoa (PB)?

Partindo da perspectiva da educação como um direito subjetivo de todos, temos como objetivo da pesquisa analisar as conquistas e desafios frente à efetividade do direito da criança à Educação Infantil no município de João Pessoa/PB. A análise será realizada a partir da observação da atual situação da Educação Infantil no município supracitado, com ênfase na verificação da garantia e efetivação do direito da criança à educação. Dessa forma, as informações que serão apresentadas configuram a realidade da Educação Infantil em João Pessoa/PB, tendo como base os dados apresentados pelos órgãos competentes: o Instituto Brasileiro de Geografia e Estatística (IBGE) e o Instituto Nacional de Estudos e Pesquisas Educacionais Anísio Teixeira (INEP).

\section{Metodologia}

O percurso metodológico deste estudo está respaldado no entendimento de metodologia como "o caminho do pensamento e a prática exercida na abordagem da realidade" (Minayo, 1994, p. 16). Partindo dessa reflexão, a abordagem metodológica deste estudo é configurada no aporte da pesquisa qualitativa de caráter bibliográfica e documental. A natureza bibliográfica deste estudo se justifica pela sua fundamentação teórica, que teve como base as pesquisas em livros e trabalhos científicos publicados. Nessa direção coincidimos com Gil (2002), pois o mesmo nos afirma que "a pesquisa bibliográfica é desenvolvida com base em material já elaborado, constituído principalmente de livros e artigos científicos” (p. 44).

Já natureza documental da pesquisa é justificada a partir da exploração das fontes documentais que serão realizadas, tendo em vista que a pesquisa será conduzida, em diversos momentos, por análises de documentos oficiais. Acerca da pesquisa documental, Gil (2002) nos afirma que: “[...] a pesquisa documental vale-se de materiais que não recebem ainda um tratamento analítico, ou que ainda podem ser reelaborados de acordo com os objetos da pesquisa" (p. 45).

O referencial teórico, e consequentemente a pesquisa bibliográfica deste estudo, foi fundamentado à luz de Dias (2008), Ruiz (2007) e Fernandes \& Candau (2017). No campo da pesquisa documental apresentamos uma discussão em torno da legislação nacional educacional vigente: Constituição Federal (CF/1988), o Estatuto da Criança e do Adolescente (ECA/1990), a Lei de Diretrizes e Bases da Educação Nacional (LDBEN/1996), o Referencial Curricular Nacional para a Educação Infantil (RCNEI/1998), as Diretrizes Curriculares Nacionais para a Educação Infantil (DCNEI/2009) e os Planos Nacionais de Educação (PNE/2001; PNE/2014). Além disso, se discute os dados presentes no portal do Instituto Brasileiro de Geografia e Estatística (IBGE), do Instituto Nacional de Estudos e Pesquisas Educacionais Anísio Teixeira (INEP).

\section{Políticas Públicas Brasileiras: a Efetividade do Direito das Crianças à Educação}

Ao falar de creche, em seu contexto histórico, é unânime afirmar que ela foi criada como espaço de cuidados às crianças que tinham as suas mães inseridas no mercado de trabalho. No mundo, a origem das creches está intimamente relacionada à Revolução Industrial que se deu no século XVIII na Europa.

Nesse contexto, o atendimento à criança surge diante do desenvolvimento do capitalismo e da industrialização, tendo em vista a necessidade da liberação das mulheres para o trabalho. Assim, "o surgimento das instituições de educação infantil, portanto, encontra-se fortemente vinculado às modificações que a família sofreu dentro das sociedades, mais especificamente às mudanças do papel da mulher dentro do contexto das sociedades burguesas” (Dias, 2008, p. 175). Esse trabalho nas fábricas, por sua vez, acarretou alguns problemas circunstanciais dos quais se destacaram a falta de higiene adequada e os altos índices de mortalidade infantil. Sobre isso, Ruiz (2007) acrescenta que: 
O objetivo principal das primeiras creches instaladas no Brasil era o de reduzir os enormes índices de mortalidade infantil, através do fornecimento de abrigo, alimentação e alguns cuidados médico-higiênicos para as crianças, elas passam, com o tempo, a também liberar a força de trabalho feminina (Ruiz, 2007, p. 105).

A creche surgiu com uma proposta de cunho assistencialista, detendo a sua visão e seus objetivos para questões de guarda, cuidado, alimentação e higiene das crianças pobres. Sendo assim, o atendimento em creche surge, inicialmente, com o objetivo de conter os alarmantes índices de mortalidade das crianças que ainda não eram aproveitadas como força de trabalho pelo mundo fabril. No entanto, é com o fim do regime militar no Brasil que se inicia uma nova fase da Educação Infantil, esta, agora, respaldada e consolidada por meios constitucionais e garantidores do direito à educação de qualidade para a criança pequena. Nessa perspectiva, crescem os estudos fundamentados na noção de criança como sujeito ativo de seu processo de aprendizagem, reafirmando a concepção de criança como sujeito de direitos e da Educação Infantil enquanto direito da criança (Dias, 2008, p. 173).

Nessa direção, nos últimos tempos, a Educação Infantil foi conquistando espaços no âmbito das políticas públicas e também de fóruns, debates e congressos educacionais. Por sua vez, as políticas públicas brasileiras, no contexto da Educação Infantil, nos remetem à superação do caráter assistencialista que se fez tão predominante nas instituições de atendimento à criança e foi na defesa do caráter educacional que a legislação brasileira começou a apresentar mudanças significativas quanto à educação em seus textos.

No que se refere à Educação Infantil, um dos marcos mais significativos da legislação brasileira foi a aprovação, em 1988, da CF/88, pois esta assegura a doutrina da Declaração dos Direitos da Crianças de 1959 e reconhece a educação, em creche e pré-escolas, como direito da criança e um dever do Estado a ser cumprido nos sistemas de ensino.

Art. 205. A educação, direito de todos e dever do Estado e da família, será promovida e incentivada com a colaboração da sociedade, visando ao pleno desenvolvimento da pessoa, seu preparo para o exercício da cidadania e sua qualificação para o trabalho.

Art. 208. O dever do Estado com a educação será efetivado mediante a garantia de: [...]IV - educação infantil, em creche e pré-escola, às crianças até 5 (cinco) anos de idade [...].

Art. 227. É dever da família, da sociedade e do Estado assegurar à criança, ao adolescente e ao jovem, com absoluta prioridade, o direito à vida, à saúde, à alimentação, à educação, ao lazer, à profissionalização, à cultura, à dignidade, ao respeito, à liberdade e à convivência familiar e comunitária, além de colocá-los a salvo de toda forma de negligência, discriminação, exploração, violência, crueldade e opressão (BRASIL, 1988).

No leque da legislação brasileira de promoção à Educação Infantil às crianças, encontra-se o Estatuto da Criança e do Adolescente (ECA), instituído pela Lei no 8.069 de 13 de julho de 1990, que reafirma os direitos fundamentais da criança e dos adolescentes presentes no texto da Constituição Federal, dentre os quais o acesso à educação.

Art. $4^{\circ}$ É dever da família, da comunidade, da sociedade em geral e do poder público assegurar, com absoluta prioridade, a efetivação dos direitos referentes à vida, à saúde, à alimentação, à educação, ao esporte, ao lazer, à profissionalização, à cultura, à dignidade, ao respeito, à liberdade e à convivência familiar e comunitária.

Art. 53. A criança e o adolescente têm direito à educação, visando ao pleno desenvolvimento de sua pessoa, preparo para o exercício da cidadania e qualificação para o trabalho [...]

Art. 54. É dever do Estado assegurar à criança e ao adolescente:

[...]IV - atendimento em creche e pré-escola às crianças de zero a seis anos de idade [...] (Brasil, 1990).

Nesse sentido, a educação não era mais assistencialista e/ou compensatória e sim um direito que tem como foco o desenvolvimento pleno desse sujeito. A CF/88 e o ECA foram marcos de consolidação do direito da criança à educação que culminam, em 20 de dezembro de 1996, na Lei de Diretrizes e Bases da Educação Nacional (LDBEN), instituída pela Lei de nº 9.394. Esta legislação trouxe, pela primeira vez, a denominação da Educação Infantil como sendo primeira etapa da educação 
básica em nosso país:

Art. $4^{\circ} \mathrm{O}$ dever do Estado com educação escolar pública será efetivado mediante a garantia de: I - educação básica obrigatória e gratuita dos 4 (quatro) aos 17 (dezessete) anos de idade, organizada da seguinte forma: a) - pré-escola; II - educação infantil gratuita às crianças de até 5 (cinco) anos de idade. (Brasil,1996).

A referida Lei, em consonância à $\mathrm{CF} / 88$ e ao ECA, traz um salto qualitativo frente ao reconhecimento da criança enquanto sujeito de direitos à educação, pois apresenta como finalidade o desenvolvimento integral da criança em seus aspectos físicos e psicológicos, intelectuais e sociais, considerando a criança como um ser completo e indivisível. Além disso, apresenta a Educação Infantil como complemento à ação da família e da comunidade e não mais como substituta desses contextos sociais, fato que se caracteriza, portanto, como um avanço no reconhecimento legal do atendimento educacional às crianças pequenas.

À luz da LDB, o MEC, em 1998, elaborou o Referencial Curricular Nacional para a Educação Infantil (RCNEI). Este documento, ao longo de todo o seu texto, se mostra como sendo uma política de qualidade do atendimento prestado na Educação Infantil, tendo em vista que “[...] o Referencial pode funcionar como elemento orientador de ações na busca da melhoria de qualidade na educação infantil brasileira [...]” (Brasil, RCNEI, v.1, 1998, p. 14).

Nesse ínterim, o RCNEI traz uma concepção integrada de Educação Infantil, destacando que a creche deve ser uma instituição que apresente e tenha como finalidade o cuidado e a educação de crianças pequenas. Essa integração é defendida pelo Referencial por meio da concepção de indissociabilidade entre as ações de cuidado e educação das crianças. Além disso, nos direciona acerca dos conceitos dessas práticas:

Educar significa, portanto, propiciar situações de cuidados, brincadeiras e aprendizagens orientadas de forma integrada e que possam contribuir para o desenvolvimento das capacidades infantis de relação interpessoal, de ser e estar com os outros em uma atitude básica de aceitação, respeito e confiança, e o acesso, pelas crianças, aos conhecimentos mais amplos da realidade social e cultural (Brasil, RCNEI, v.1, 1998, p.23).

Nesse sentido, o RCNEI nos faz compreender que se deve cuidar e educar a criança como sendo um indivíduo que está em contínuo desenvolvimento. Ademais, nos alerta quanto à superação das ainda existentes práticas assistencialistas de guarda e cuidado nas instituições de Educação Infantil, tendo em vista que a Educação Infantil hoje é concebida como um espaço institucional educativo que apresenta como fundamento pedagógico a indissociabilidade entre o cuidar e o educar, objetivando o desenvolvimento integral da criança pequena (Dias, 2008, p.177).

No campo das políticas públicas para a educação, um marco importante que refletiu na Educação Infantil foi a promulgação da Lei no 10.172, de 09 de janeiro de 2001, que aprova o Plano Nacional de Educação (PNE/2001). A aprovação e elaboração de um plano voltado para a educação responderam exigências já previstas na CF/88 com a Lei nº 9.131 , de 24 de novembro de 1995 e na LDBEN/96.

No que diz respeito à sua organização, o PNE de 2001 teve capítulo específico dedicado à Educação Infantil. O texto dos objetivos e metas é claro e procura sinalizar como essa etapa precisa ser organizada. De uma forma geral, pode-se dizer que o conjunto de objetivos e metas trata de quatro grandes assuntos: inclusão educacional das crianças nos seus diferentes níveis (creche e pré-escola), infraestrutura, formação inicial e continuada (formação em serviço) e, por último, financiamento.

Dentre os principais objetivos temos a seguinte determinação:

1. Ampliar a oferta de educação infantil de forma a atender, em cinco anos, a 30\% da população de até 3 anos de idade e $60 \%$ da população de 4 e 6 anos (ou 4 e 5ano) e, até o final da década alcançar a meta de $50 \%$ das crianças de 0 a 3 anos e $80 \%$ das de 4 e 5 anos (Brasil, 2001). 
Outro documento que norteia os princípios garantidores do direito da criança à educação é a Resolução CNE/CEB n ${ }^{\circ}$ 5, de 17 de dezembro de 2009 que fixa as Diretrizes Curriculares Nacionais para a Educação Infantil com o intuito de "[...] orientar as políticas públicas na área e na elaboração, planejamento, execução e avaliação de propostas pedagógicas e curriculares" (BRASIL, DCNEI, 2009). No decorrer do texto, as Diretrizes (2009) reafirmam a LDB e o conceito de criança como sujeito de direitos e parte principal do processo educativo e do planejamento curricular dizendo:

Art $4^{\circ}$ As propostas pedagógicas da Educação Infantil deverão considerar que a criança, centro do planejamento curricular, é sujeito histórico e de direitos que, nas interações, relações e práticas cotidianas que vivencia, constrói sua identidade pessoal e coletiva, brinca, imagina, fantasia, deseja, aprende, observa, experimenta, narra, questiona e constrói sentidos sobre a natureza e a sociedade, produzindo cultura (Brasil, 2009).

Dessa forma, as Diretrizes apresentam a visão da criança como sujeito social e histórico de direitos, capaz de produzir cultura através de suas mais diversas interações sociais e que se pauta em princípios éticos, políticos e estéticos, além de destacar o Brasil como um país em busca da efetividade do direito da criança à educação de qualidade.

Na tentativa de atingir os objetivos e metas não alcançados no PNE de 2001 e tendo em vista que este Plano tem duração decenal, temos, no ano de 2014, a aprovação do novo Plano Nacional de Educação (PNE 2014-2024), instituído pela Lei N $N^{0}$ 13.005, que substitui o PNE/2001. Apesar de sua tardia aprovação, o PNE/2014 traça metas e estratégias que visam à expansão do acesso e à melhoria da qualidade na Educação Infantil.

Meta 1: universalizar, até 2016, a educação infantil na pré-escola para as crianças de quatro a cinco anos de idade e ampliar a oferta de educação infantil em creches de forma a atender, no mínimo, cinquenta por cento das crianças de até três anos até o final da vigência deste PNE (Brasil, 2014).

Diante de todo o exposto, é possível considerar que as recentes políticas públicas para a Educação Infantil concebem grandes conquistas quanto à efetividade do direito da criança à educação de qualidade. A partir da CF/88, dá-se início a essa gama de conquistas já então alcançadas, mas ainda são muitas as conquistas e os desafios a serem enfrentados, pois não basta afirmar que a criança é sujeito de direitos e que a Educação Infantil é direito dessa criança, é preciso, também, criar as condições necessárias para que toda e qualquer família que queira possa matricular seu filho em uma instituição de Educação Infantil pública, gratuita, de qualidade e que respeite o direito da criança de ser educada (Dias, 2008, p.184).

Assim, compreendemos que as atuais políticas públicas caracterizam um avanço histórico na concepção da efetividade do direito da criança à educação e trazem saltos qualitativos quanto ao reconhecimento desta como sendo sujeito de direitos.

\section{Educação Infantil: do Direito Adquirido ao Direito Negado}

O direito à educação vem de uma luta histórica no contexto dos direitos humanos. No rol das políticas públicas, este direito emerge como uma conquista social alcançada que, mesmo diante dos desafios, possui muitas conquistas e iniciativas para a sua efetivação. No que concerne ao direito de todos à educação, a Declaração Universal dos Direitos Humanos vem afirmar tal garantia na década de 40:

Art. 26 - 1. Todo ser humano tem direito à instrução. A instrução será gratuita, pelo menos nos graus elementares e fundamentais. A instrução elementar será obrigatória. A instrução técnico-profissional será acessível a todos, bem como a instrução superior, esta baseada no mérito (ONU, 1948). 
Na Declaração Universal dos Direitos Humanos (1948), a educação como um direito humano universal aparece no mesmo patamar do direito à vida, à segurança, à paz, à saúde e ao bem-estar, assim como os direitos humanos são concebidos com princípio e conteúdo do direito à educação (Fernandes \& Candau, 2017, p.3).

Nesse contexto, a Constituição Federal de 1988 afirma, também, o direito à educação. Para ela, a educação é instituída como sendo um direito social, conforme explícito em seu artigo 6": "São direitos sociais a educação, a saúde, a alimentação, o trabalho, a moradia, o transporte, o lazer, a segurança, a previdência social, a proteção à maternidade e à infância, a assistência aos desamparados, na forma desta Constituição" (Brasil, 1988).

Partindo do pressuposto da educação como direito de todos, aqui irá se analisar como se dá a efetivação do direito subjetivo da criança à Educação Infantil pública, gratuita e de qualidade no município de João Pessoa/Paraíba. A respeito do citado município, temos as seguintes informações: apresenta, conforme o Censo do IBGE (2010), uma população de 723.515 habitantes, bem como uma população estimada de 817.511 pessoenses no ano de 2020.

No âmbito da Educação Infantil, os dados do Censo Demográfico de 2010 são relativos à cobertura no atendimento educacional de crianças de zero a cinco anos. Conforme esses dados, a população residente de crianças de zero a cinco anos no município de João Pessoa é dividida da seguinte forma: de zero a três anos resultam no total de 40.155 habitantes, de quatro anos são 10.577 e de cinco anos são 10.761 crianças.

Com o objetivo de retratar quantitativamente a realidade mais atual da Educação Infantil, no município de João Pessoa (PB), a seguir apresentaremos os dados educacionais do IBGE referente ao ano de 2018, no que diz respeito ao quantitativo de docentes, de instituições e de matrículas na Educação Infantil. Esses dados podem ser observados na Tabela 1 a seguir:

Tabela 1 - Dados da Educação Infantil do município de João Pessoa - IBGE.

IBGE 2018- Dados Educacionais Município De João Pessoa (PB)

\begin{tabular}{c|c|c|c|c|c|c}
\hline \multicolumn{4}{c|}{ CRECHE } & \multicolumn{3}{c}{ PRÉ-ESCOLA } \\
\hline & Docentes & Instituições & Matrículas & Docentes & Instituições & Matrículas \\
\hline $\begin{array}{c}\text { Pública } \\
\text { Municipal }\end{array}$ & 268 & 81 & 6.605 & 372 & 122 & 6.059 \\
\hline $\begin{array}{c}\text { Pública } \\
\text { Federal }\end{array}$ & 5 & 1 & 39 & 4 & 1 & 48 \\
\hline Privada & 235 & 117 & 3.320 & 489 & 159 & 7.640 \\
\hline TOTAL & 508 & 199 & 9.964 & 861 & 282 & 13.747 \\
\hline
\end{tabular}

Fonte: Autores, a partir dos dados do IBGE (2018).

A partir dos dados apresentados, podemos verificar que a Educação Infantil, no município de João Pessoa (PB), caminha rumo à superação da predominância da rede privada de ensino na oferta educacional para as crianças. No que se refere à educação das crianças de 0 a 3 anos de idade, em creche, a rede pública municipal apresenta números expressivos em relação à quantidade de matrículas efetivadas no ano de 2018. Os números referentes ao quantitativo de docentes na rede municipal e privada de ensino não apresentam tamanha disparidade, mas, ainda sim, a rede municipal se sobrepõe à privada. Por outro lado, no que diz respeito às instituições, a rede privada apresenta uma quantidade superior de unidades educativas que ofertam a educação para as crianças de tenra idade em relação à rede municipal de ensino.

No tocante à educação pré-escolar, no ano de 2018, a rede privada de ensino se destaca no município, pois os dados que a colocam em sobreposição à rede municipal são significativos quanto ao número de docentes, instituições e matrículas. Diferente da realidade apresentada nas creches, as matrículas da pré-escola na rede privada superam as da rede municipal de ensino em aproximadamente $26 \%$. No que concerne ao número de docentes e instituições, ambos os dados apresentam uma 
sobreposição de aproximadamente 30\% da rede privada em relação à rede pública do município de João Pessoa.

Diante disso, é possível perceber que a rede privada de ensino apresenta mais esforços no processo de efetivação da educação pré-escolar. Tal análise se fundamenta na obrigatoriedade da educação a partir dos 4 anos de idade, referenciada legalmente pela própria $\mathrm{CF} / 88$ e por meio da Lei $\mathrm{n}^{\circ} 12.796$, de 2013, mas, principalmente, por ser a pré-escola a etapa educacional que antecede o grande alvo de rendimentos e lucros que é a oferta do Ensino Fundamental.

Objetivando a apreensão da realidade e uma reafirmação dos dados acerca da Educação Infantil no município de João Pessoa (PB) realizamos, também, uma pesquisa no portal no INEP. A partir dos dados pesquisados, apresentaremos uma análise do quantitativo de matrículas na Educação Infantil do município de João Pessoa (PB) dando ênfase ao comparativo de expansão da primeira etapa da Educação Básica nas dependências públicas municipais e federais e nas dependências da rede privada. Estes dados serão representados na Tabela 2 a seguir.

Tabela 2 - Dados do número de matrículas na Educação Infantil - João Pessoa (PB) - INEP.

Número de matrículas na Educação Infantil - João Pessoa (PB)

\begin{tabular}{c|c|c|c|c|c|c|c|c|c}
\hline \multicolumn{9}{c}{ Etapa de Ensino / Dependência Administrativa } \\
\hline & \multicolumn{3}{c}{ Creche } & \multicolumn{4}{c}{ Pré-Escola } \\
\hline Ano & $\begin{array}{c}\text { Total } \\
\text { E.I. }\end{array}$ & Federal & Municipal & Privada & Total & Federal & Municipal & Privada & Total \\
\hline $\mathbf{2 0 1 4}$ & $\mathbf{2 0 . 1 6 7}$ & 28 & 4.271 & 3.253 & 7.552 & 42 & 4.929 & 7.644 & 12.615 \\
\hline $\mathbf{2 0 1 5}$ & $\mathbf{2 1 . 3 8 5}$ & 50 & 5.041 & 3.421 & 8.512 & 58 & 5.027 & 7.788 & 12.873 \\
\hline $\mathbf{2 0 1 6}$ & $\mathbf{2 2 . 0 1 4}$ & 40 & 5.456 & 3.187 & 8.683 & 56 & 5.299 & 7.976 & 13.331 \\
\hline $\mathbf{2 0 1 7}$ & $\mathbf{2 2 . 5 1 5}$ & 55 & 6.294 & 3.054 & 9.403 & 60 & 5.450 & 7.602 & 13.112 \\
\hline $\mathbf{2 0 1 8}$ & $\mathbf{2 3 . 7 1 1}$ & 39 & 6.605 & 3.320 & 9.964 & 48 & 6.059 & 7.640 & 13.747 \\
\hline
\end{tabular}

Fonte: Autores, a partir dos dados do INEP (2018).

Os dados expressos na tabela retratam uma realidade ainda distante de uma Educação Infantil para todos. Tomando como referência os dados do censo do IBGE de 2010 no município de João Pessoa (PB) quanto ao número de crianças do presente ano, temos a existência de 40.155 crianças na faixa etária de 0 a 3 anos. Desse total, de acordo com os dados da Tabela 2, apenas 9.964 crianças foram matriculadas no último ano de 2018, tomado como referência por ser o ano mais recente. Essa realidade da pouca oferta educacional às crianças pequenas é ainda mais dura quando se analisa os números de matrículas na rede pública de ensino, já que correspondem a apenas 6.644 crianças matriculadas na Educação Infantil pública de 0 a 3 anos de idade.

No contexto da pré-escola podemos inferir uma realidade bem aproximada. Ainda fazendo referência ao censo de 2010, é possível observar a existência de 21.338 crianças na faixa etária de 4 e 5 anos de idade. Quando se analisa esse quantitativo frente ao número de matrículas efetivadas no ano de 2018, na pré-escola, é notório que apenas $51 \%$ desse grupo de crianças encontram-se inseridas na realidade educacional. Esse percentual reflete um total de 13.747 matrículas efetivadas na pré-escola, das quais apenas 6.107 foram de crianças matriculadas na rede pública de ensino.

Outro ponto que merece destaque é que, mesmo a creche municipal apresentando um aumento significativo de mais de 500 matrículas a cada ano, isso não interfere no aumento das matrículas das creches da rede privada, bem como a rede municipal não consegue manter o mesmo quantitativo de matrículas da creche para a pré-escola, pois os dados revelam que a cada ano a pré-escola da rede pública perde algumas matrículas em comparação aos dados da creche, exceto nos anos de 2015 e 2016. 
Esse fator acarreta aumentos significativos nas matrículas da pré-escola da rede privada, as quais, quando comparadas ao número de matrículas da rede pública, apontam uma discrepância de mais de mil alunos que não têm acesso ao ensino gratuito. Além da expressiva ausência das nossas crianças no contexto da Educação Infantil, é válido destacar a presença marcante da rede privada de ensino que retrata a realidade da incapacidade do Poder Público do município de João Pessoa (PB) em garantir a educação como sendo um direito público e subjetivo de todas as crianças.

Desse contexto podemos compreender que, apesar da expansão do atendimento educacional à criança pequena ser uma realidade, ainda se está distante da efetivação da universalização da Educação Infantil às crianças de 4 e 5 anos e do atendimento no mínimo de 50\% das crianças de 0 a 3 anos até 2024, conforme previsto no PNE de 2014.

Todos os dados analisados nesta pesquisa fazem refletir acerca da situação atual da Educação Infantil no município de João Pessoa (PB). Os números e as reflexões citadas revelam a contradição existente entre os objetivos proclamados e os objetivos realmente alcançados, o que nos leva a uma reflexão acerca da não efetividade do direito da criança à educação e nos faz enxergar o expressivo número de crianças que ainda não gozam do direito público e subjetivo à Educação Infantil pública, gratuita e de qualidade.

\section{Considerações Finais}

O objetivo principal desta pesquisa foi analisar as conquistas e desafios frente à efetividade do direito da criança pequena à educação. Os dados analisados na pesquisa revelam a atual situação da Educação Infantil no município de João Pessoa/PB, tendo em vista que foram analisados os seguintes aspectos quantitativos: população de zero a cinco anos, número de instituições, de docentes e de matrículas nas redes de ensino.

As reflexões acerca desses dados indicam que a Educação Infantil, no âmbito do citado município, não tem sido priorizada nem efetivada como um direito subjetivo da criança pequena. Tal realidade é representada a partir do grande número de crianças que ainda não usufruem desse direito constitucionalmente expresso. Tendo como base o estudo da legislação nacional vigente, podemos refletir acerca dos avanços que ocorreram nesse âmbito legislativo, porém ainda há muito que ser feito em prol da efetivação do direito da criança à educação pública, gratuita e de qualidade.

Logo, a análise dos dados traz um alerta para a atual situação da Educação Infantil no município de João Pessoa/ PB. Além dos dados quantitativos apresentados, também se faz importante considerar que, para a efetivação de uma educação de qualidade, é preciso refletir acerca de aspectos qualitativos que se mostram como importantes, como: a formação das gestoras e das educadoras, os contratos de prestação de serviços existentes no âmbito educacional, a falta de vagas na rede municipal de ensino e, consequentemente, o número insuficiente de instituições de Educação Infantil, dentre outros aspectos que são relevantes para a efetivação do direito da criança pequena à educação de qualidade, tendo em vista que esses pontos destacados, e os que estão subentendidos, refletem diretamente no direito à educação e sua qualidade.

Diante disto, enfatizamos que, mesmo partindo da compreensão da criança como sujeito de direitos e da educação de qualidade como um direito subjetivo desse sujeito, nos deparamos com a não efetivação desse direito em sua plenitude e com a certeza de que se terá, ainda, muitos desafios a enfrentar em busca dessa efetivação.

Ponderando a relevância da temática, o nosso objeto de estudo não está esgotado. Uma das possibilidades de continuidade da pesquisa está na investigação das contradições entre a garantia do direito ao acesso e a permanência da criança na Educação infantil pública, gratuita e de qualidade, frente a uma gestão governamental que rege políticas de contenção e redução da qualidade. Desta maneira, serão necessários maiores aprofundamentos em estudos futuros.

\section{Referências}

Brasil. (1988). Constituição da República Federativa do Brasil. Diário Oficial da União. Brasília. 
Research, Society and Development, v. 10, n. 1, e21410111540, 2021 (CC BY 4.0) | ISSN 2525-3409 | DOI: http://dx.doi.org/10.33448/rsd-v10i1.11540

Brasil. (1990). Lei no 8.069, de 13 de julho de 1990. Dispõe sobre o Estatuto da Criança e do Adolescente e dá outras providências. Diário Oficial da União. Brasília.

Brasil. (1996). Lei n 9.394, de 20 de dezembro de 1996.Estabelece as Diretrizes e Bases da Educação Nacional. Diário Oficial da União. Brasília.

Brasil. (1998). Referencial Curricular Nacional para a Educação Infantil. SEF/MEC, Brasília.

Brasil. (2001). Lei no 10.172, de 09 de janeiro de 2001. Aprova o Plano Nacional de Educação e dá outras providências. Diário Oficial da União. Brasília.

Brasil. (2009). Diretrizes Curriculares Nacionais para a Educação Infantil. CNE/MEC, Brasília.

Brasil. (2014). Lei no 13.005, de 25 de junho de 2014.Aprova o Plano Nacional de Educação- PNE e dá outras providências. Diário Oficial da União. Brasília.

Dias, A. A. (2008). Infância e direito à educação. In: Bittar, E. C. B; Tosi, G. (Org.). Democracia e educação em direitos humanos numa época de insegurança. <http://www.cchla.ufpb.br/ncdh/wp-content/uploads/2015/11/DEMOCRACIA.DH_.EPOCA_.INSEGURAN\%C3\%87A.pdf>

Fernandes, Y. S., \& Candau, V. M. F. (2017). Direito à qualidade da educação e educação em direitos humanos: inter-relações e desafios. Educação, (40), (1), $2-9$.

Gil, A. C. (2002). Como elaborar projetos de pesquisa. (4a ed.) Atlas.

IBGE. Ensino: matrículas, docentes e rede escolar 2015. https://cidades.ibge.gov.br/v4/brasil/pb/joao-pessoa/pesquisa/13/5902?detalhes=true\&ano=2015

INEP. Sinopses Estatísticas da Educação Básica. http://portal.inep.gov.br/web/guest/sinopses-estatisticas-da-educacao-basica

Minayo, M. C. S. (1994). Ciência, técnica e arte: o desafio da pesquisa social. In: Minayo, M. C. S. (Org.). Pesquisa social: teoria, métodos e criatividade. Vozes.

Nações unidas. (1948). Declaração Universal dos Direitos Humanos. http://unesdoc.unesco.org/images/0013/001394/139423por.pdf

Ruiz, J. S. (2007). Creche: um discurso acerca de seu surgimento. http://cpan.ufms.br/old/encontro_pedagogia/2_Comunicacao_Oral/Comu08.pdf

Saviani, D. (2013). História das ideias pedagógicas no Brasil. (4a ed.): Autores Associados. 